\title{
A Comparative Research on the Management of Foreign Students in China and the Management of Students in Other Countries
}

\author{
Yang $\operatorname{Lin}^{1, *}$ \\ ${ }^{1}$ International Education College, Jilin Agricultural University, Changchun, Jilin, China, 130118
}

Keywords: foreign students; convergence management; comparative study; education; management

\begin{abstract}
The management of foreign students in mainland universities is a new subject facing China's education since the founding of new China, especially since the reform and opening-up. The increasing number of foreign students on the one hand represents the vigorous development of China's cultural and educational undertakings. On the other hand, it also makes the mainland universities face more challenges in student management. China's mainland university convergence management is still in the development stage, mainly in the school and the grassroots level, two levels of management institutions and personnel, usually taking a controlled management model. In contrast, the management of foreign and Hong Kong and Taiwan regions has been quite mature, colleges and universities in Europe and the United States tend to professional management at the school level, Hong Kong and Taiwan are the school and grassroots professional management at the same time. Therefore, the mainland colleges and universities should "seek common points while reserving difference" on the basis of the status quo, adhere to "almost the same" direction, learn from colleges and universities of Europe and the United States, Hong Kong and Taiwan at the same time, to further increase the support of grassroots student organizations, consolidate and carry forward the advantages of our college counselor system.
\end{abstract}

\section{Introduction}

With the development of society, globalization has become a topic that every earth cannot avoid. The world in economic, political, cultural, diplomatic and other aspects contact more and more closely. China as a developing country, especially since 1979, since the reform and opening up with many countries and regions in the world have established a good diplomatic relations in the direction of internationalization continue to move forward[1]. At the same time, many colleges and universities in China have followed the trend of the world and recruited foreign students as an important task for the development of schools[2]. More and more foreign students also chose to explore the treasure trove of knowledge in China. Studies have shown that China officially began to recruit foreign students began in the 1950s.

In the second year of the founding of new China, in order to strengthen exchanges and cooperation with the socialist countries, our government has agreed to exchange students with Poland, Czechoslovakia, Romania, Hungary and Bulgaria, which came to China at the end of 1950, in order to open our country to accept and cultivate foreign students precedent[3-4]. "Then our country to accept the work of foreign students has been developing, especially since the 20th century, 70 years with China's reform and opening up foreign students who have come to China are gradually increasing. The foreign students who are increasingly diversified in China are increasingly becoming a large group[5]. "2008 statistics show that as of 2008 China's total of 189 countries and regions from the 23 leap 49 foreign students since the founding of new China since the number of foreign students in China, the largest number of countries and regions, to receive foreign students in Chinese schools and institutions up to a year."

With the increasing number of foreign students coming to China, the relevant departments and scholars of the country have become more and more concerned about the "foreign students". After the 1980s, the state has introduced a series of policies to promote foreign students to come to China[6]. The scholars of the Luo dynasty also discussed the relationship between foreign students 
and the political, economic, cultural and educational development of foreign students from their own professional perspectives[7]. In addition, the management of foreign students in colleges and universities as a basis for the study of foreign students in the field of pooling sociologists, educators, anthropologists, university policy researchers and other relevant researchers interest. Especially in recent years to celebrate the management of foreign students papers published in the author of the 37 papers published in 2009 after the papers accounted for 24 and published in 200 years ago, only two. However, despite the current academic community for foreign students in the management of foreign students continue to improve, there are some very insightful observations and suggestions but in the study but often overlooked the voice of foreign students have really put their own into this Both about the interests of colleges and universities, but also related to their own interests in the project[8].

\section{Convergence of overseas student management goals, and challenge the status}

\subsection{The mode of education and management of international students in China}

"China's long-term education reform and development plan (2010-2020)" pointed out: "to strengthen international exchanges and cooperation. Adhere to open to promote reform and promote development. To carry out multi-level, wide-ranging educational exchanges and cooperation, The level of internationalization of education to further expand the scale of foreign students to increase the number of scholarships of the Chinese government, focusing on financing students in developing countries to optimize the structure of studying abroad students to study in China to prepare for education, to increase the teaching of foreign language courses, Improve the quality of education in China. " At present, China's education and management of foreign students mainly concentrated in institutions of higher learning. There are two main categories of students who are studying in China. They are international students for the purpose of obtaining various professional degrees. One is to study and study Chinese culture and language for non-degree students. In terms of educational economics, "the education of foreign students in China is of great significance to promote trade in educational services, reduce the huge deficit in China's international education service trade, increase the 'extra-budgetary income' of universities and change the educational resource structure of colleges and universities, improve the efficiency of education management. So it is of great significance to improve the internationalization and development of the local education.

The enrollment, education and management of the current student groups in China are basically carried out by colleges and universities. Non-degree students and degree students are enrolled in the university to study, it should be noted that the inter-school exchange students in colleges and universities is a special group, these students may be both institutions to cultivate the degree of students, or may be China's short-term study of non-student students. With the increasing number of international students, many colleges and universities have set up a similar "Chinese Language Education Center" to facilitate the school to meet the requirements of the students for Chinese tuition. Generally speaking, the current institutions of higher education in China and non-degree management of foreign students take two models.

Mode A: A comprehensive college with a special function of education and management is set up by the institutions of higher learning. It is responsible for the enrollment and management of students in the school, and is responsible for the education and management of students and nondegree Chinese learners. In this model, the size of the comprehensive college is usually large, a lot of subordinate departments, the administrative aspects of the administrative department, the admissions department, the student affairs department, the degree students and non-degree students, various project management departments, Confucius Institute affairs Departments, etc .; teaching, in addition to meet the Chinese professional education related to the formal teachers and researchers, but also includes a large number of informal off-campus staff.

Mode B: set up by the institutions of higher learning students management center / center (referred to as "stay"), unified management of the whole school students enrollment, accommodation (multi-service students), visas and other specific related matters. Professional 
degree of foreign students to teach and to school for the Chinese language, the University of Foreign Languages, the Chinese Academy of Sciences, Learning non - degree students teaching and management affairs.

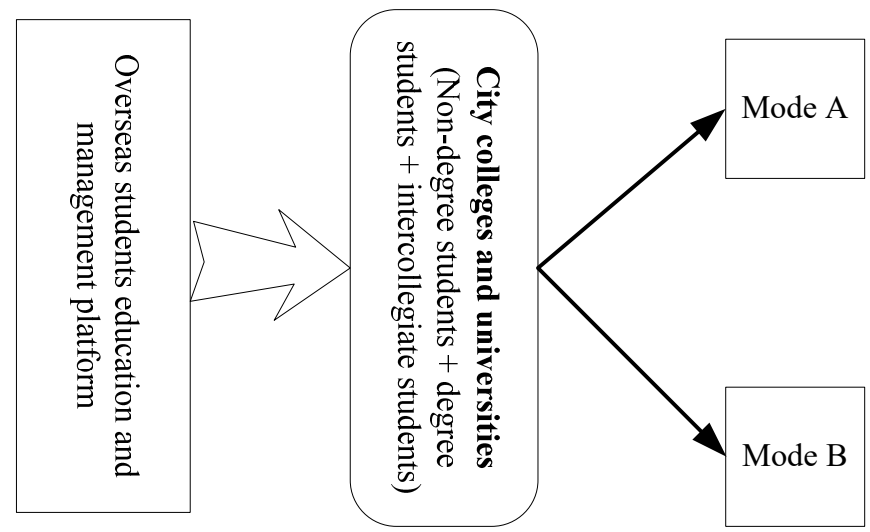

Figure 1. Overseas students education and management platform

\subsection{The goal, challenge and status of convergence management}

The goal of convergence management is to "seek the same", that is, to allow students and Chinese students to get the same level of education quality, into the cultural atmosphere of China, to accept and agree with China's various systems. Compared with the guidance of graduate students, the education management of undergraduates should focus on cultivating the universal recognition of Chinese students. Through the ideological and political education, cultural exchange activities, to help the poor work, mental health education, career development education, to help students and Chinese students together to experience life, understanding of life, self-awareness.

The challenge of convergence management is "much different" and the gap between "different" and "same" has not been significantly reduced. The cultural background, religious beliefs, customs and knowledge of foreign students in China are very different. Colleges and universities must combine the different characteristics of the students to teach students, to further improve the management system. However, the construction of the system requires a long period of exploration, trial and error and accumulation, and the growth rate of our students is not weakened, the existing students "cultural shock" and other incompatibility phenomenon has not been properly resolved. $\mathrm{w}$ visible in the current and future period of time, to promote the convergence of better and faster management is necessary to move.

Table 1. Four dimensions of cultural differences indicators of some countries

\begin{tabular}{|l|c|c|c|c|}
\hline $\begin{array}{l}\text { Dimension } \\
\text { country }\end{array}$ & $\begin{array}{c}\text { Individualism } \\
\text { index }\end{array}$ & $\begin{array}{c}\text { Power } \\
\text { distance } \\
\text { index }\end{array}$ & $\begin{array}{c}\text { Uncertainty } \\
\text { circumvent }\end{array}$ & Maleism index \\
\hline China & 22 & 64 & 48 & 52 \\
\hline United States & 91 & 43 & 45 & 63 \\
\hline Korea & 87 & 61 & 84 & 40 \\
\hline Pakistan & 14 & 56 & 70 & 52 \\
\hline Germany & 66 & 36 & 64 & 67 \\
\hline East Africa & 26 & 65 & 51 & 42 \\
\hline West Africa & 19 & 78 & 53 & 47 \\
\hline Arabian countries & 37 & 81 & 67 & 54 \\
\hline Venezuela & 11 & 82 & 75 & 74 \\
\hline
\end{tabular}

The status of convergence management is "same". In order to achieve the goal of convergence is a long-term process, in the process of real management, colleges and universities should not only manage the way of Chinese students "to" the management of international students, but also encourage, support and promote students to participate in all kinds of understanding of China, contacting with China's special activities, but also efforts to keep students to maintain their own 
characteristics. For example, focus on the "student culture show activities", according to the situation of foreign students to carry out certain special management, including the development of appropriate management measures and policies.

Culture is a common psychological process in people in an environment, not an individual characteristic, but a psychological program that has many of the functions of the same educational and life experience. Different groups, regions, or countries have different procedures. According to Hofstedt, cultural differences can be divided into four dimensions: power distance, uncertainty avoidance, individualism and collectivism, and masculine versus femininity.

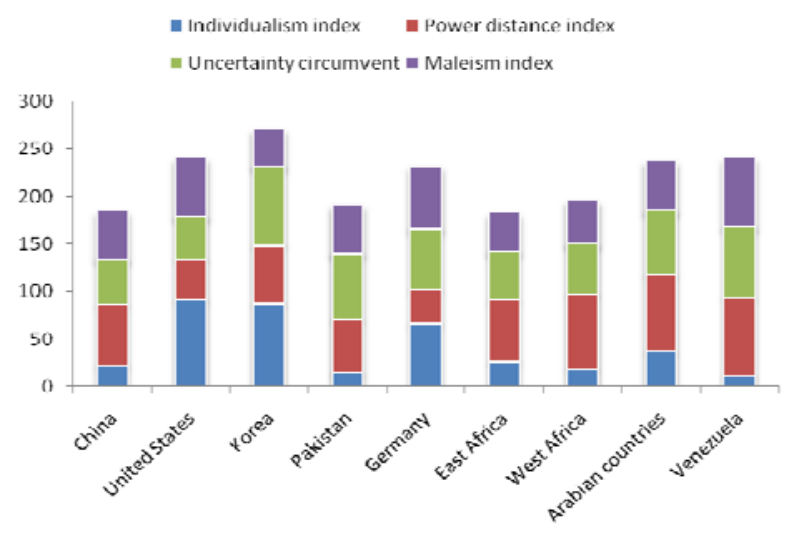

Figure 2. Four dimensions of cultural differences indicators of some countries

\section{A comparative analysis of the convergence management model of Chinese and foreign students}

In order to improve the quality of foreign students' convergence management, to speed up the pace of integration of Chinese and foreign students and to overcome the challenges encountered in the management process, it is necessary to understand the international well-known high school students in the process of integration of foreign students experience, combined with China's national conditions to learn from each other The In this paper, we selected the eight universities in the world as the comparative study of the convergence of foreign students, namely: University of California, University of Science and Technology, University of Dublin, the Mexican Monterrey Technology and other five foreign universities, as well as the University of Hong Kong, Taiwan University and Fudan University, three Chinese universities. So it provide a reference for the integration of foreign students in mainland China.

\subsection{The degree of development is different: the convergence of maturity and the convergence of development}

Generally speaking, the goal of convergence of Chinese and foreign universities is no different, but the degree of development is quite different: the management of colleges and universities in Europe and America and Hong Kong and Taiwan are more mature, and the management of universities in mainland China is in the process of development.

Europe and the United States and China's Hong Kong and Taiwan high school mature management, is based on a strong economic strength, with advanced educational philosophy as a guide to a strong campus culture as a link. This is the main symbol of mature management is: First of all, due to the higher threshold of college entrance, the school will generally recruit students to default to have achieved a certain degree of "homogenization", they and their students the quality, ability is basically no different, So the school does not provide students with the convergence of the strong sense of management, its management model is mainly rely on the professional management of the school, the service sector to provide services for students. Second, the students selfmanagement atmosphere, especially for the school to support students to students, associations in all forms of cultural exchange activities. Societies vary in size, but play a synergistic management 
role for the school level of large associations, increase the opportunity for students to exercise independently to enhance the quality of self-education students.

Table 2. A Comparative Study of International Student Management in Different Countries

\begin{tabular}{|c|c|c|c|c|}
\hline Area & School & $\begin{array}{l}\text { Development } \\
\text { level }\end{array}$ & $\begin{array}{l}\text { Management } \\
\text { personnel }\end{array}$ & $\begin{array}{l}\text { Management } \\
\text { style }\end{array}$ \\
\hline $\begin{array}{l}\text { Europe and the } \\
\text { United States }\end{array}$ & $\begin{array}{l}\text { University of California } \\
\text { University of Birmingham } \\
\text { University of Dublin } \\
\text { Tampere University } \\
\text { Monterrey University of } \\
\text { Technology }\end{array}$ & mature & SCHOOL & professional \\
\hline $\begin{array}{l}\text { China } \\
\text { Hong Kong and } \\
\text { Taiwan }\end{array}$ & $\begin{array}{l}\text { Hong Kong university } \\
\text { Taiwan University }\end{array}$ & mature & $\begin{array}{l}\text { School + } \\
\text { grassroots }\end{array}$ & professional \\
\hline mainland of China & Fudan University & developing & $\begin{array}{l}\text { School + } \\
\text { grassroots }\end{array}$ & Controlled \\
\hline
\end{tabular}

In contrast, the mainland schools in the development process have a clear tendency to actively promote the convergence of management by the strength of all parties in the school. As the current foreign students come to the mainland to study the uneven, and with the Chinese students there are "different and less" gap, and the level of education is an important basis for assessing the overall level of education in colleges and universities, the general management of students more Attention. For example, Fudan University to international students education as "the school to create a worldclass university an important part of", "constantly reform and innovation students enrollment, training, management and other work initiatives for Chinese and foreign students to build a common learning, harmonious development, leading to the future Of the road to talent. " The School of Foreign Students' Affairs Office is responsible for the work of the students from the enrollment to the whole process of school management. The departments and the relevant functions of the schools are responsible for the specific implementation of the work of students studying, living, foreign affairs and finance during their studies.

Table 3. The nationality of students studying in China

\begin{tabular}{rrrrrrr}
\hline & Poland & Russia & Kazakhstan & Kyrgyzstan & Korea & Total \\
\hline 2014 & 2 & 5 & 7 & 10 & 3 & 20 \\
2015 & 1 & 1 & 22 & 2 & 4 & 23 \\
2016 & 1 & 4 & 18 & 3 & 10 & 29 \\
\hline
\end{tabular}

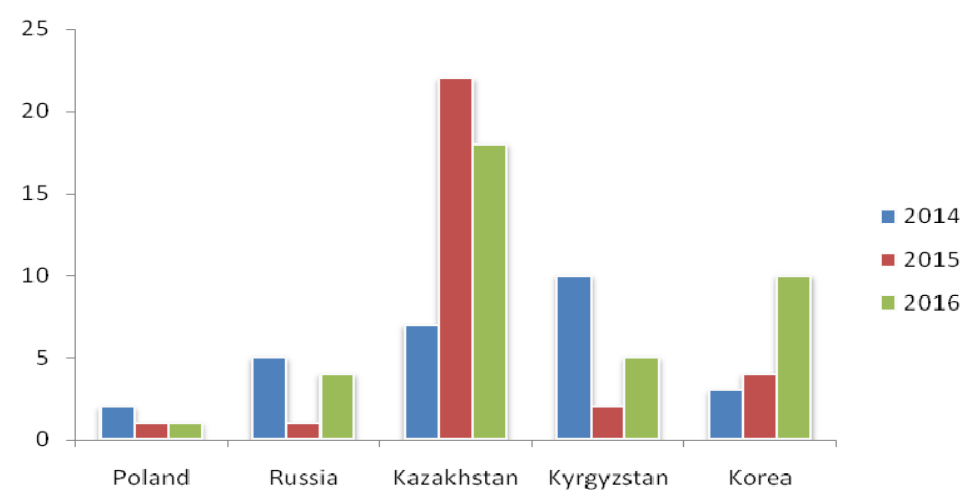

Figure 3. The nationality of students studying in China 


\subsection{The differences between the management agencies: school-level management and management of grass-roots organizations}

The eight colleges and universities in this study have administrative institutions in charge of student affairs at the school level (such as the International Education Center of the University of California, the International Office of the University of Dublin, the International Affairs Office of the University of Taiwan, the Foreign Student Affairs Office of the University of Fudan University, etc.). To coordinate the management of foreign students, and other functional departments of the school to coordinate the specific teaching, research, life and other matters, and rely on student associations to carry out student exchange activities. However, the lack of grassroots students in foreign universities (such as class, dormitory) manage student affairs, especially rare mainland college "counselors" a class of grassroots student management. In contrast, school-level staff will not be as active as counselors, take care to manage the students' affairs. Functional departments of the staff configuration less, are "sitting class" the nature of the work, students need to take the initiative to consult.

Hong Kong and Taiwan universities generally use student dormitories such grassroots students to organize the convergence of management. In each of the dormitories of the University of Taiwan, there are management instructors who, in addition to ensuring the daily operation of Loudong, will organize a wealth of activities such as "National Youth" and "Water" will organize targeted activities to help students understand each other exchanges. Monterrey University of Mexico also implements a dormitory management model, but the number of students staying less. Fudan University is currently promoting the Fudan University "college building" undergraduate cultural construction, but the coverage has not yet involved in international students. The faculties are still in the class as a unit, with counselors as the core management personnel, to bear the management of international students.

\subsection{The difference between management: control management and professional management}

Mainland university undergraduate management is very extensive, including thinking, such as political education, cultural exchange activities, helping the poor students, mental health education, career development education, and professional mentor to share the functions of academic guidance. This comprehensive management approach is similar to the preparation of a table for students "Manchu seats", is based on the traditional "paternalistic" management philosophy, through the role of centralized counselor to be implemented. At present, the trend of the convergence of foreign students in mainland China is to integrate the above management contents into the management of international students. The main drawback is that the management effect is "unattainable" and the management personnel are not caught. The management is very different.

Europe and the United States, Hong Kong and Taiwan colleges and universities do not have a clear ideological and political education, as to help the poor work, mental health education, career development education and other work by the relevant departments of the school directly responsible. These schools attach particular importance to academic guidance and set up grassroots teachers to guide small-scale students such as the Tutor of the University of Hong Kong and the University of Birmingham, the Coordinator of the University of Tampere, the Lecturer of the University of Dublin, University of California graduate student assistant and so on. These supervisors are mostly exquisite graduate students or young teachers, the main responsibilities include guiding students to deal with elective affairs, supervise students to complete academic work, organize students to carry out classroom discussions, students in a model of the general image, the guiding role is obvious. In addition, these schools tend to carry out cultural exchange activities through travel, cultural parties and other forms. For example, Birmingham University often organizes short trips to Oxford University and Cambridge University on weekends. This prerequisite for "professional", "menu-style" management is that students have the initiative to seek help and service awareness, the system of protection is the effective division of the school units, close cooperation and high-quality professionals. 


\section{The Improvement Measures of Convergence Management in Mainland China}

\subsection{Improve the principle: understanding the gap, to maintain the characteristics}

We must realize that the convergence of foreign students in mainland universities and the current level of international advanced level there is still a big gap between the performance of the institutions to be integrated and perfect, the professional division of labor to be strengthened, the individual ability to be improved. We must fully understand and understand these gaps, but also strive to make up for this gap. The management of international students must not be completely divorced from the mode and thinking of Chinese students 'management. According to the current situation of the management of Chinese students and the management of students in China, we should learn from the characteristics of Chinese students' management and maintain a certain degree of Chinese management. For example, colleges and universities should fully study the experience of colleges and universities in Hong Kong and Taiwan, and continue to increase their support for grassroots students' organizations such as "class" and "life park", and encourage foreign students to fully integrate into the Chinese student community. According to the Chinese characteristics of the counselor system, the faculties can also further improve the cross-class student counselors system. The access conditions should be overseas study, life experience, with strong language communication skills. Can alleviate the work pressure of existing counselors, but also to promote the sharing of experience between counselors, to promote the development of personalized counseling, which greatly enhance the efficiency and quality of students convergence management.

\subsection{To maintain the "same" different status quo, firm "almost the same" direction}

"Convergence management" cannot be regarded as equivalent culture. In view of China's economic and social development level is not high, the exchange of foreign exchange is also in the exploratory stage, which is foreign, Hong Kong and Taiwan universities are very different. Therefore, the mainland colleges and universities should be appropriate to continue to maintain the "same" different management status, and steadily carry out the "moderate convergence" management. In view of the special status of foreign students, colleges and universities should not only consolidate the common management of Chinese and foreign students in teaching and student activities, so that students, students and students in China to produce close collective recognition, but also seriously consider the ideological and political education.

We must realize that over-relaxation is not appropriate for the ideological education of foreign students, which is contrary to the comprehensive cultivation of talented people's purpose, but also to the Chinese students living environment caused unnecessary interference. Colleges and universities should strengthen Chinese laws and regulations, excellent traditional culture and national conditions education, to help overseas students to understand China's social development. We should vigorously cultivate the Chinese political connotations and proficiency in the use of foreign language professionals, students can accept the way to teach China's political knowledge, to eliminate foreign students on China's political philosophy and institutional misunderstanding. In short, the colleges and universities should strive to cultivate a group of "knowledge", "Friends of foreign" student management personnel, fully understand the religious beliefs of students, cultural habits, traditional ideas, students used to manage the way to be managed, Narrow the distance with the students.

For the improvement of foreign students and the improvement of the direction of improvement measures, many scholars have been from the theoretical and practical point of view were described. For example, in the process of ideological education, aiming at the characteristics of students' legal system and adopting the idea of administering the rules according to the rules, we should strengthen the ideological education while establishing and perfecting the rules and regulations. In implementing the principle of "being different", language training, cultural guidance and institutional adaptation should be strengthened. In the management process, should strengthen communication, clear functions, improve the level of refinement. These views from the macro dimension to grasp the connotation and essence of the integration of management.

Colleges and universities should further promote the support of the grassroots management of 
foreign students, in particular, should firmly grasp the training of foreign students and other relevant personnel training, team building, so as to give full play to the creativity of the student work team, the management objectives will be implemented, will face challenges Solved. We must study the institutions of the institutions of Hong Kong and Taiwan to consolidate the cohesive function of the grassroots students in the class, and to study the academic tutor system of the European and American colleges and universities, to strengthen the professional qualities of the students' management, to attract more knowledge and familiarity with foreign countries. Of course, the mainland universities should fully combine their own advantages and school situation, and gradually explore with their own characteristics of the convergence of the management model, and through the full exchange of communication between the high schools.

\section{Conclusion}

In the context of the increasing number of international students coming to China and the increasingly complex language and culture of foreign students, the students and managers of international students must take effective measures to adjust and effectively solve the problem of cross-cultural adaptation of international students according to the new situation. Colleges and universities to set up by the International Students Office of the psychological counseling room and language training courses for students to build a spiritual harbor, can effectively prevent and timely treatment of students psychological and language adaptation issues; teachers as the main academic support system for Students to provide more professional knowledge of the information, can effectively and effectively solve the problem of academic adaptation of students; and students as the main building a wide range of student associations, students can broaden their understanding and understanding of Chinese society and culture path, to a certain extent Can also solve the problem of Chinese culture to adapt.

\section{Acknowledgement}

This work was supported by 2017 Jilin Province Department of Education "thirteen" social science research project: Jilin Province to China students scholarship project management status quo and countermeasures research (project number: JJKH20170331SK) stage research results. The Cultural Conflict and Fusion of Chinese and Foreign Students in the Context of Educational Internationalization - Taking Jilin University as an Example (Project No. JJKH20170325SK).Jilin Province Education Science "13th Five-Year Plan" 2016 annual topic: the local university international core competitiveness of the research and practice (project number: GH16211).

\section{References}

[1] Hofstede G. Cultural constraints in management theories[J]. The Academy of Management Executive, 1993, 7(1): 81-94.

[2] Saw G, Abbott W, Donaghey J, et al. Social media for international students-it's not all about Facebook[J]. Library Management, 2013, 34(3): 156-174.

[3] Abdullah D, Aziz M I A, Ibrahim A L M. A "research" into international student-related research:(Re) Visualising our stand?[J]. Higher Education, 2014, 67(3): 235-253.

[4] Woodall T, Hiller A, Resnick S. Making sense of higher education: students as consumers and the value of the university experience[J]. Studies in Higher Education, 2014, 39(1): 48-67.

[5] Choudaha R, Chang L, Kono Y. International student mobility trends 2013: Towards responsive recruitment strategies[J]. 2014.

[6] Cooke F L, Saini D S, Wang J. Talent management in China and India: A comparison of management perceptions and human resource practices[J]. Journal of World Business, 2014, 49(2): 225-235. 
[7] Kaplan A. European management and European business schools: Insights from the history of business schools[J]. European Management Journal, 2014, 32(4): 529-534.

[8] Wan Y K P, Wong I K A, Kong W H. Student career prospect and industry commitment: The roles of industry attitude, perceived social status, and salary expectations[J]. Tourism Management, 2014, 40: 1-14. 